Disponível em

http://www.anpad.org.br/rac

RAC, Rio de Janeiro, v. 19, n. 6, art. 1, pp. 673-695, Nov./Dez. 2015

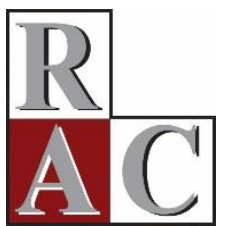

\title{
Orientação Empreendedora: Um Estudo das Dimensões e sua Relação com Desempenho em Empresas Graduadas
}

\section{Entrepreneurial Orientation: A Study of Dimensions and its Relationship with Performance at Firms Graduating from Incubators}

Fábio Lazzarotti Universidade do Oeste de Santa Catarina - UNOESC

Alissane Lia Tasca da Silveira Faculdade Municipal de Palhoça - FMP

Carlos Eduardo Carvalho Universidade do Oeste de Santa Catarina - UNOESC

Carlos Ricardo Rossetto Universidade do Vale do Itajaí - UNIVALI

Jonatha Correia Sychoski Universidade do Oeste de Santa Catarina - UNOESC 


\title{
Resumo
}

O artigo analisou a orientação empreendedora (OE) em suas dimensões - comportamento inovador, assunção de riscos, proatividade, autonomia, agressividade competitiva e redes de relações - e sua associação com o desempenho das empresas graduadas das incubadoras brasileiras. De modo específico, objetivou-se comparar os resultados desse estudo com o encontrado por A. C. M. Z. Santos e Alves (2009), a partir dos modelos de Miller (1983) e Lumpkin e Dess (1996). Utilizou-se a abordagem quantitativa e a técnica de modelagem de equações estruturais para uma amostra de 128 empresas do Brasil. Os principais resultados evidenciaram que a OE constituise como um modelo unidimensional, divergente do encontrado por A. C. M. Z. Santos e Alves (2009) em empresas incubadas. Verificou-se que a dimensão que contribuiu mais fortemente para a existência da OE foi a autonomia, e que as redes de relações, dimensão não mencionada até então pelos estudos anteriores, colaboraram de forma análoga às demais dimensões para a composição da $\mathrm{OE}$.

Palavras-chave: dimensões da orientação empreendedora; empreendedorismo; desempenho; empresas graduadas; redes de relações.

\begin{abstract}
The article analyzed the entrepreneurial orientation (EO) in its dimensions - innovative behavior, risk taking, proactiveness, autonomy, competitive aggressiveness and networks of relationships - and its association with the performance of firms that have graduated from Brazilian incubators. Specifically, this study aimed to compare its results with those found by A. C. M. Z. Santos and Alves (2009), from Miller's models (1983) and Lumpkin and Dess (1996). We used a quantitative approach and the technique of structural equation modeling for a sample of 128 Brazilian firms. The main results showed that EO is on a unidimensional model, which diverges from that found by A. C. M. Z. Santos and Alves (2009) in incubated firms. We found that the dimension which strongly contributed to the existence of EO was independence and that networks of relationships, a dimension heretofore unmentioned in previous studies, worked similarly to other dimensions for EO composition.
\end{abstract}

Key words: entrepreneurial orientation dimensions; entrepreneurship; performance; firms graduating from incubators; networks of relationships. 


\section{Introdução}

O empreendedorismo é um campo de estudo amplo, que tem avançado para diferentes áreas do conhecimento. Entre os precursores dos estudos em torno deste tema, há uma convergência dos pesquisadores para os nomes de Richard Cantillon e Jean-Baptiste Say como os precursores a trabalharem com este tema. Para alguns, Cantillon é considerado o criador do termo empreendedorismo, conforme Hisrich e Peters (2004). Entretanto, foi Say quem ficou conhecido como o pai do empreendedorismo por ter sido ele que, primeiro, lançou as bases de estudo desse campo (Filion, 1999).

Destaca-se também o economista Joseph Alois Schumpeter, a quem se credita a clara associação do empreendedorismo com a inovação. Embora Schumpeter não tenha sido o único a fazer essa associação, ele é considerado um dos principais expoentes do assunto no campo dos economistas. Schumpeter foi um dos primeiros a estabelecer uma diferenciação conceitual entre gerentes, proprietários de pequenos negócios e empreendedores (Carland, Hoy, Boulton, \& Carland, 1984). Em uma de suas principais obras, Teoria do Desenvolvimento Econômico (Schumpeter, 1983), o autor aborda o empreendedor enquanto indivíduo responsável por realizar combinações novas na economia, demonstrando a importância dos empreendedores para a explicação do crescimento econômico.

Essa capacidade de realização, de empreender e de gerar mudanças na economia e na sociedade, em decorrência da atitude do empreendedor, pode ser verificada também no nível organizacional. Embora a ênfase dos estudos normalmente tenha recaído sobre o indivíduo, o trabalho de Miller (1983) demonstra que a atividade empresarial muitas vezes ultrapassa o esforço de um gestor-chave da organização. De acordo com o autor, o crescimento constante das organizações e a necessidade premente de buscar oportunidades, de inovar e de assumir riscos tornou imprescindível a atuação da organização como um todo no processo de empreender. Dentro desse enfoque, a atividade empreendedora no nível organizacional é definida como orientação empreendedora, constituindo-se em um ramo de estudo do campo do empreendedorismo (Covin \& Slevin, 1989; Grégoire, Noël, Déry, \& Béchard, 2006; Martens \& Freitas, 2008; Miller, 1983).

O estudo da orientação empreendedora $(\mathrm{OE})$ tem despertado o interesse de muitos pesquisadores, especialmente para verificar possíveis associações com o desempenho das empresas, conforme mostra o trabalho de Martens e Freitas (2008). Miller (1983) foi um dos pioneiros a demonstrar a correlação do desempenho em empresas orientadas para atuar de maneira empreendedora. No Brasil, também foram realizados diversos trabalhos com o propósito de investigar a $\mathrm{OE}$, relacionados à performance empresarial (A. C. M. Z. Santos \& Alves, 2009; Fernandes \& Santos, 2008; Martens \& Freitas, 2008; Mello, Paiva, Souza, \& Lubi, 2006). Em especial, o estudo empírico de A. C. M. Z. Santos e Alves (2009) foi tomado como base na aplicação da presente pesquisa.

A investigação de A. C. M. Z. Santos e Alves (2009) teve o objetivo de avaliar a OE e sua relação com o desempenho nas empresas incubadas de incubadoras tecnológicas do sul do Brasil, a partir do modelo de Miller (1983) e Lumpkin e Dess (1996). O resultado da pesquisa das autoras evidenciou que a $\mathrm{OE}$ possui dimensões que contribuem de forma independente no desempenho e, dentre as dimensões da OE, o comportamento inovativo foi a que mais impactou no desempenho das empresas. Entretanto, percebeu-se que a maioria das que foram pesquisadas (60\%) tem menos de 2 anos, o que tende a caracterizar este comportamento inovativo para quem está no início das atividades empresariais, especialmente nas organizações alocadas em incubadoras, que são espaços favoráveis ao desenvolvimento e à difusão da inovação (Etzkowitz, 2002).

Em geral, o processo de incubação de empresas compreende três fases: pré-incubação, incubação e pós-incubação (graduação). Na fase de pré-incubação, as empresas ou os empreendedores elaboram seus planos de negócios e estudos de mercado, visando avaliar a viabilidade do novo negócio, bem como se preparar para a gestão do futuro empreendimento. A incubação é a fase de implementação do negócio, da introdução no mercado dos novos produtos, serviços ou processos. Em ambas as fases, principalmente durante a incubação, os empreendimentos recebem apoio tecnológico, de gestão e acompanhamento pela incubadora. A última fase é denominada pós-incubação ou graduação do 
empreendimento. Ela significa que o negócio alcançou maior maturidade na gestão das atividades organizacionais, podendo reduzir o vínculo ou desvincular-se da incubadora e passar a atuar com recursos próprios (Abreu, Souza, \& Gonçalo, 2006).

Nesse sentido, o objetivo da investigação consistiu em analisar o comportamento empreendedor e sua relação com desempenho das empresas graduadas nas dimensões - comportamento inovador, assunção de riscos, proatividade, autonomia e agressividade competitiva - acrescido de uma sexta dimensão: rede de relações, que não foi investigada por A. C. M. Z. Santos e Alves (2009) e por estudos anteriores. De modo específico, objetivou-se comparar os resultados deste estudo com o encontrado por A. C. M. Z. Santos e Alves (2009).

Pretendeu-se, ainda, verificar se o comportamento inovativo manter-se-á nas graduadas, e em que medida, bem como se outras dimensões da OE serão relevantes em empresas com maior tempo de existência, que é o caso das empresas graduadas. Como são empresas que passaram pelo processo de incubação, provavelmente encontram-se em outro estágio de desenvolvimento dos seus negócios. Destarte, o artigo visa contribuir com o teste de novas hipóteses, por conta da inclusão da dimensão de rede de relações e talvez encontrar outras evidências empíricas ao ampliar o campo de pesquisa, para ir além da replicação do modelo de estudo de A. C. M. Z. Santos e Alves (2009).

De modo a alcançar tal intento, estruturou-se o artigo em cinco tópicos principais. O primeiro é o que trata da introdução, na qual se faz a apresentação inicial do tema e dos objetivos da pesquisa. No segundo tópico, descrevem-se as bases teóricas do tema empreendedorismo, fala-se de orientação empreendedora e suas respectivas dimensões, para fundamentar o estudo, seguido das hipóteses da pesquisa. Na sequência, apresenta-se a metodologia utilizada para testar as hipóteses, constituindo-se o terceiro tópico do artigo. O quarto tópico discute os resultados decorrentes da pesquisa e o quinto apresenta as considerações finais, trazendo as principais conclusões e limitações da investigação. Ao final, descrevem-se as referências utilizadas no estudo.

\section{Referencial Teórico e Hipóteses}

Nesta seção, descreve-se o referencial teórico utilizado para fundamentar a pesquisa, que tem por base os temas de empreendedorismo e as dimensões da orientação empreendedora, em um total de seis, com suas respectivas definições e trabalhos teórico-empíricos relacionados. Em seguida, apresentam-se as hipóteses de pesquisa que nortearam a condução da investigação.

\section{Empreendedorismo}

Empreendedorismo, segundo Dolabela (1999a, p. 43), "é um neologismo derivado da livre tradução da palavra entrepreneurship e utilizado para designar os estudos relativos ao empreendedor, seu perfil, suas origens, seu sistema de atividades, seu universo de atuação". Desde o advento da utilização do termo empreendedor, principalmente a partir do início do século $\mathrm{XX}$, até os dias atuais, é possível perceber distintamente, por vezes complementar, dois campos ou correntes de estudo: a dos economistas e a dos humanistas. Em geral, os economistas fazem a associação do empreendedor com a inovação, conforme descrito na seção de introdução ao estudo. Os humanistas, especialmente os comportamentalistas, veem o empreendedor pelos aspectos criativo e intuitivo (Filion, 1999).

O termo empreendedorismo tem origem francesa, entrepreneur, utilizado no século XII para designar aquele que incentivava rivalidades (Vérin, 1982 como citado em Dolabela, 1999b). A semântica francesa influenciou a utilização do termo inglês entrepreneurship, o qual é considerado por Stoner e Freeman (2009) como um processo de combinar recursos para produção de bens e serviços. Desse modo, a função dos entrepreneurs (empreendedores) consiste na capacidade de tomar os fatores de produção, quais sejam: terra, trabalho e capital, usando-os para produção de bens e serviços. 
Diferenciam-se os entrepreneurs por perceberem oportunidades em situações que outros agentes não percebem.

Dolabela (1999b) realça que Cantillon, em 1755, definiu o empreendedor como alguém que comprava matéria-prima com o objetivo de fazer o processamento da mesma e depois revender por um preço maior, atribuindo ao empreendedor a imagem de alguém que assumia riscos, aproveitando oportunidades com o objetivo de obter lucros, representando este aspecto um desafio.

O ímpeto em empreender está atrelado à predisposição ao desafio. Assim é que McClelland (1962) considera que uma pessoa exposta a uma oportunidade desafiadora, coloca-se como disposta ao trabalho em busca de um objetivo. O inconformismo daqueles que têm a necessidade de realização, com a situação vigente, funciona como um impulso à atividade. No entanto, há que se lembrar também outro perfil menos empreendedor psicologicamente, ao qual as oportunidades desafiadoras tornam-se indiferentes.

Considerando o aspecto psicológico comportamental, manifesta-se Tranjan (2003) no seguinte teor:

A maneira como escolhemos olhar para o mundo ao redor molda tanto a nossa mente como o nosso coração. O mesmo vale para as empresas: a maneira como seus dirigentes escolhem olhar para o mercado e, a partir daí, atuar, determina o seu destino de sucesso ou fracasso (p. 16).

Um ambiente de mudanças pode contribuir ao sucesso organizacional aos empreendedores que vislumbram nela um meio de para obtenção de sucesso. "Os entrepreuneurs veem a mudança como a norma e como algo saudável. Geralmente não são eles próprios que trazem a mudança. Porém o entrepreneur sempre procura mudanças, reage a elas, e as explora como se fossem oportunidades" (Drucker, 1986, p. 27, tradução nossa). Assim, pelo relato do autor, tem-se que os empreendedores geralmente não são inventores, mas aqueles que aplicam a invenção, a mudança, por encontrarem nela uma oportunidade, no sentido de romper com o tradicional, o rotineiro.

Gonçalves (2003, p. 19) entende que "empreender enseja quebrar uma lógica de mercado, modificar uma dinâmica até então válida e oferecer ao mercado um negócio realmente novo. Não é por outro motivo que inovação e criatividade andam de braços dados com o empreendedorismo".

A capacidade de produzir de uma nação é capaz de evidenciar o grau de transformação do espaço geograficamente habitado. E, sobre a transformação espacial, considera M. Santos (1977) que as formações sociais devem ser compreendidas no contexto dinâmico, composto por variáveis que interagem na modificação do espaço.

A produção, capaz de transformar esse espaço, deve atender as necessidades em bens e serviços da população, a qual com seu próprio esforço criativo possivelmente inibe problemas de cunho econômico e social. Schumpeter (1983), um dos principais autores da área de empreendedorismo e da inovação e um dos precursores dos estudos nesse campo, demonstra a importância dos empreendedores para o desenvolvimento econômico, conforme salientado na introdução deste estudo. Em outra obra de Schumpeter (1942), menciona-se o processo de destruição criativa como algo impulsionador do capitalismo. Esse processo, segundo o autor, é responsável pelo desuso de alguns objetos em detrimento de outros, em virtude da criatividade capaz de substituir um produto ou serviço de maior custo e menor eficiência por outro mais barato e que melhor atenda as necessidades a que se dispõe.

Sob essa ótica, consideram-se as incubadoras de empresas como mecanismos de auxílio no desenvolvimento econômico regional para estimular e criar empresas inovadoras. As incubadoras são organizações que têm por finalidade fornecer apoio a uma empresa nova, disseminando o empreendedorismo, proporcionando infraestrutura para assessoria e apoio ao empreendedor na gestão de sua empresa. Além do apoio e da assessoria, a rede de contatos que a incubadora pode disponibilizar, facilita o desenvolvimento dos negócios. 
Destaca Leite (2006) que a importância da existência das incubadoras de empresas, está justamente na oportunização de ambientes empresariais de risco baixo ou moderado, permitindo um maior encorajamento ao empreendedor para inovação voltada à transformação de ideias em produtos e serviços, possibilitando o aumento das chances de sobrevivência.

\section{Orientação empreendedora}

Os estudos da orientação empreendedora ou empreendedorismo no nível organizacional tiveram como base, principalmente, o trabalho de Miller (1983). O autor reconhece a importância do líder, do sujeito que empreende, mas acrescenta o papel desempenhado pela estrutura da organização e a importância da construção da estratégia, deslocando a ênfase das capacidades inovadoras do indivíduo, que tem sido abordada na maioria dos estudos para a atividade empreendedora da empresa.

Miller (1983) observou que o desempenho das empresas está associado à orientação empreendedora (OE). Empresas menos dispostas a assumir comportamentos empreendedores, tendem a obter resultados inferiores àquelas que atuam sob a $\mathrm{OE}$. Para mensurar e testar o empreendedorismo nas organizações, o autor identificou três dimensões: assumir riscos, proatividade e comportamento inovador.

Nota-se que a construção dessas dimensões apresentadas por Miller (1983) tem como base o trabalho seminal de Schumpeter (Martens \& Freitas, 2008). Mais tarde, a OE é analisada por Lumpkin e Dess (1996), que entendem que o empreendedorismo, para avaliar sua relação com o desempenho organizacional, pode ser mais bem compreendido, considerando a inclusão de mais duas dimensões, em complemento às que foram propostas por Miller (1983), quais sejam: autonomia e agressividade competitiva.

Assim, pode-se dizer que as dimensões ora mencionadas são responsáveis pela construção conceitual de OE. Ela trata da ação empreendedora a partir do método ou da forma em que a organização atua nas tomadas de decisões e de gestão das atividades empresariais, mensuradas pelas dimensões da OE.

Ao tecer sobre cada uma das dimensões, inicia-se pela disposição das empresas em assumir riscos. Existe praticamente um consenso entre os teóricos de que o comportamento empreendedor implica, necessariamente, numa aceitação de risco de alguma espécie (McClelland, 1972). Tem-se a propensão de assumir riscos como fator essencial ao empreendedorismo. Para Fernandes e Santos (2008), o risco está relacionado à disposição da alta gerência em atribuir grande porcentagem de recursos da firma a novos projetos e incorrer em débito pesado no desenvolvimento de oportunidades. O risco assumido pode ser entendido como o nível até o qual o empreendedor compromete recursos.

As iniciativas relacionadas à busca antecipada por novas oportunidades, bem como para participar em mercados emergentes, são entendidas por Lumpkin e Dess (1996) como proatividade. O comportamento proativo está associado à iniciativa do indivíduo na busca de oportunidades. "Assim, proatividade pode ser crucial para uma OE porque ela sugere uma perspectiva de olhar adiante que é acompanhada por atividades inovativas ou novos negócios" (Martens \& Freitas, 2008, p. 97).

Em relação à terceira dimensão proposta por Miller (1983), comportamento inovador, verificase uma relação com a abordagem teórica do empreendedorismo por Schumpeter (1983), que vê o empreendedor como o sujeito que inova, ou seja, que cria e desenvolve novas combinações na economia. Leite (2006) destaca os processos educativos, enquanto recursos fundamentais para gerar a ação inovadora, a qual pode ser canalizada com o objetivo de maximizar a produção de riqueza, como um processo socioeconômico, capaz de propiciar o desenvolvimento.

O comportamento inovador desenvolve-se com a predisposição para avaliar e identificar oportunidades, bem como a criatividade. Todo e qualquer ensejo associado à observação de negócios no intuito de se identificarem oportunidades está relacionado à predisposição empreendedora do indivíduo. Nesse sentido, assevera Degen (1989): 
O empreendedor de sucesso é aquele que não se cansa de observar negócios, na constante procura de novas oportunidades, seja no caminho de casa, do trabalho, nas compras, nas férias, lendo revistas, jornais ou vendo televisão.... Sabe que suas chances de sucesso aumentam com este conhecimento, e que o sucesso só vem para quem trabalha duro para consegui-lo (p. 20).

Ao considerar-se o comportamento inovador com criatividade, tem-se que o empreendedor é capaz de associar as observações diversificadas dos tipos e formas de empreendimentos (Degen, 1989). A criatividade empreendedora decorre da observação e associação de ideias, buscando a aplicabilidade, a tendência da necessidade em relação ao segmento que se pretende desenvolver.

Há também a análise do comportamento inovador com o cunho da psicologia. Desse modo, Stoner e Freeman (2009) apresentam que os empreendedores são complexos a tal ponto que as teorias não conseguem explicar todas as facetas do comportamento deles. Lembram os autores sobre a teoria das raízes psicológicas do empreendedorismo, preconizada por McClelland (1962), de que os indivíduos com carreiras empreendedoras possuem uma alta necessidade de realização, dispostos a correrem riscos e consequentemente sujeitos a maiores esforços.

A dimensão da autonomia é um comportamento de ação que expressa a independência do indivíduo e, na descrição de Lumpkin e Dess (1996), a autonomia se apresenta por um comportamento independente do empreendedor e pela prática de forte liderança por parte deste, refletindo, assim, um comportamento autocrático. Desse modo, trata-se da expressão volitiva do empreendedor em introduzir inovações por meio da experimentação e de processos criativos com intuito do desenvolvimento de novos produtos ou serviços (Lumpkin \& Dess, 1996). No estudo de A. C. M. Z. Santos e Alves (2009), associa-se autonomia com liberdade, considerando a necessidade da independência dos indivíduos ligada ao surgimento de novas ideias.

Outra dimensão característica dos empreendedores é o comportamento que se traduz por agressividade competitiva, e esta está relacionada à disputa com os concorrentes por posições e nichos de mercado, sendo fundamental a sobrevivência no seu mercado de atuação. Assim, A. C. M. Z. Santos e Alves (2009) lembram que o ímpeto de forçar a entrada em um mercado e desafiar a concorrência pode ser compreendido como agressividade competitiva da empresa. Os estudos de Lumpkin e Dess (1996) defendem o uso de métodos de competição não convencionais, do tipo desmerecer o competidor e, ainda, apresentam que ocorre a melhora da posição competitiva quando da entrada em mercados com preços muito baixos, copiando práticas de negócios ou técnicas de competidores de sucesso, ou marketing oportuno de anúncio de novos produtos ou tecnologias.

Uma sexta dimensão da OE, acrescentada nesta investigação, é denominada de redes de negócios ou de relações (Dolabela, 1999b; McClelland, 1962; Mello \& Leão, 2005). Trata-se de uma dimensão que assume relevância no campo do empreendedorismo, na medida em que a construção de relacionamentos torna-se imprescindível para o ingresso em novos mercados, para a internacionalização dos negócios e, inclusive, para a sustentação das organizações (Basile, 2012; Covin \& Miller, 2014; Paiva, Fernandes, \& Almeida, 2010). Analogamente, essa dimensão tem suporte teórico em outros trabalhos que avaliaram a importância da rede de relacionamentos, como a que se verifica no estudo de Zoschke e Lima (2006). Os autores realizaram um estudo do marketing empreendedor nas empresas de pequeno porte de base tecnológica e identificaram que as redes de relações são fundamentais no processo de moldar a visão e as competências dos empreendedores.

Essa prática de estabelecimento de redes de negócios no campo da inovação tende a crescer no Brasil com a Lei Nacional de Inovação, conforme mostra o estudo de Matias-Pereira e Kruglianskas (2005). A referida lei dispõe sobre incentivos à inovação e à pesquisa científica e tecnológica no ambiente produtivo, visando, desse modo, incrementar a cultura da inovação por meio da relação universidade e empresa. Neste contexto, a Lei 10.973, de 2 de dezembro de 2004, denominada Lei da Inovação, permite uma interação entre o ente público, pesquisadores e empresariado, objetivando superar gargalos à inovação, estimular o empreendedorismo científico e tecnológico, aumentar a competitividade e permitir a conquista de mercados externos. Em efeito, a celebração de parcerias ou acordos de cooperação entre as organizações ou indivíduos se apresenta como uma das principais 
práticas dos empreendimentos inovadores para a formação das redes de relações. O estudo de Oberg e Grundström (2009) descreve que a celebração de acordos de cooperação, o trabalho colaborativo na forma de parcerias, o estabelecimento de alianças estratégicas e a atuação em rede são alguns dos mecanismos utilizados pelas empresas para o desenvolvimento de inovações.

No que tange especificamente ao empreendedorismo e à viabilização de empresas graduadas, mediante o processo de incubação, o legislador preceitua sua preocupação no Art. $3^{\circ}$ e parágrafo único, in verbis:

A União, os Estados, o Distrito Federal, os Municípios e as respectivas agências de fomento poderão estimular e apoiar a constituição de alianças estratégicas e desenvolvimento de projetos de cooperação envolvendo empresas nacionais, ICT e organizações de direito privado sem fins lucrativos voltadas para atividades de pesquisa e desenvolvimento, que objetivem a geração de produtos e processos inovadores.

Parágrafo único. O apoio previsto neste artigo poderá contemplar as redes e os projetos internacionais de pesquisa tecnológica, bem como ações de empreendedorismo tecnológico e de criação de ambientes de inovação, inclusive incubadoras e parques tecnológicos (Lei $\mathrm{n}$. 10.973, 2004).

A Carta Magna, com dois artigos dispondo sobre o papel do Estado no incentivo do desenvolvimento científico, da pesquisa e da capacitação tecnológicas, representa algo significativo para que se promova maior interação entre os ambientes que produzem e utilizam o conhecimento, ou seja, o ambiente constituído pelas universidades, institutos e centros de pesquisa, e o ambiente formado pelas empresas. Sem essa interação e sem o estímulo adequado às empresas para incorporar tecnologia, a competitividade de seus produtos e processos estaria afetada (Matias-Pereira \& Krugliaskas, 2005).

A importância do sistema de relações do empreendedor também é verificada nos trabalhos de Filion (1991) e, mais recentemente, em Miller (2011). Filion (1991) entende que o desenvolvimento de uma visão empresarial está embasado nos relacionamentos do empreendedor. Segundo o autor, a construção de uma rede de relações é necessária para o planejamento de um sistema de aprendizagem e das atividades da empresa. Dificilmente a empresa crescerá sem que haja um gerenciamento efetivo das relações do empreendedor, que possibilite a evolução de sua visão.

Sob este enfoque, Jenssen e Nybakk (2009) sugerem a participação da empresa em cursos e conferências. De acordo com as autoras, cursos diferentes e específicos proporcionam às organizações oportunidades de gerar novas ideias, além de mais conhecimento. Sheng (2008), em estudo dos relacionamentos que ocorrem com empreendedores chineses no Brasil, já havia destacado também a importância da formação das relações pessoais, que denotam a importância da participação destes empreendedores em reuniões e eventos sociais para terem acesso a financiamentos. Além disso, conforme demonstram Lopes e Souza (2005), há a formação de núcleos de empreendedores e de diversas ações no Brasil que estimulam o associativismo, a capacitação empresarial, o cooperativismo, entre outros eventos, que favorecem e ampliam as redes de relações dos empreendedores.

Na abordagem teórica da corrente dos comportamentalistas, observa-se ainda que a adoção de estratégias deliberadas para influenciar os outros e/ou trabalhar com pessoas-chave como agentes para atingir objetivos são comportamentos praticados pelos empreendedores. Tais comportamentos foram pesquisados por McClelland (1972) em vários países, inclusive no Brasil, demonstrando sua relação com persuasão e poder. Em seu trabalho, o autor estabelece uma extensa analogia com a figura mitológica de Hermes, ao relacionar a capacidade de influência do empreendedor para alcançar seus próprios objetivos por meio do uso de várias estratégias e de ações persuasivas com amigos e pessoas próximas de sua rede de relacionamentos (McClelland, 1972).

Miller (2011), ao fazer uma revisita ao seu trabalho seminal (Miller, 1983), também destacou a possibilidade de algumas conexões da $\mathrm{OE}$ com outras teorias, entre as quais a de redes. $\mathrm{O}$ autor chama a atenção para algumas questões, como a do equilíbrio entre as relações com clientes, concorrentes e 
fornecedores, e sua influência sobre a OE. Miller (2011) salienta a necessidade de mais trabalhos que estudem as ligações entre a $\mathrm{OE}$ e as estruturas de rede.

\section{Hipóteses de pesquisa}

As hipóteses definidas, em geral, seguem o padrão de formação argumentado por A. C. M. Z. Santos e Alves (2009), que avalia os dois modelos de desempenho - unidimensional e multidimensional - de acordo com os pressupostos de Lumpkin e Dess (1996) e de Hughes e Morgan (2007) para o primeiro modelo, e de Miller (1983) e Covin e Slevin (1989) para o segundo modelo.

No presente estudo, porém, foi adicionada uma sexta dimensão da OE: redes de relações, conforme proposição de Mello e Leão (2005), que complementa as hipóteses investigadas por A. C. M. Z. Santos e Alves (2009). Salienta-se também que os modelos unidimensional e multidimensional foram agrupados em um único modelo, considerando a orientação empreendedora como o construto mediador entre as variáveis independentes - comportamento inovador, assunção de riscos, proatividade, autonomia, agressividade e redes de relações - e a variável dependente desempenho. A seguir, a descrição de cada uma das hipóteses, que deriva o modelo deste estudo (Figura 1).

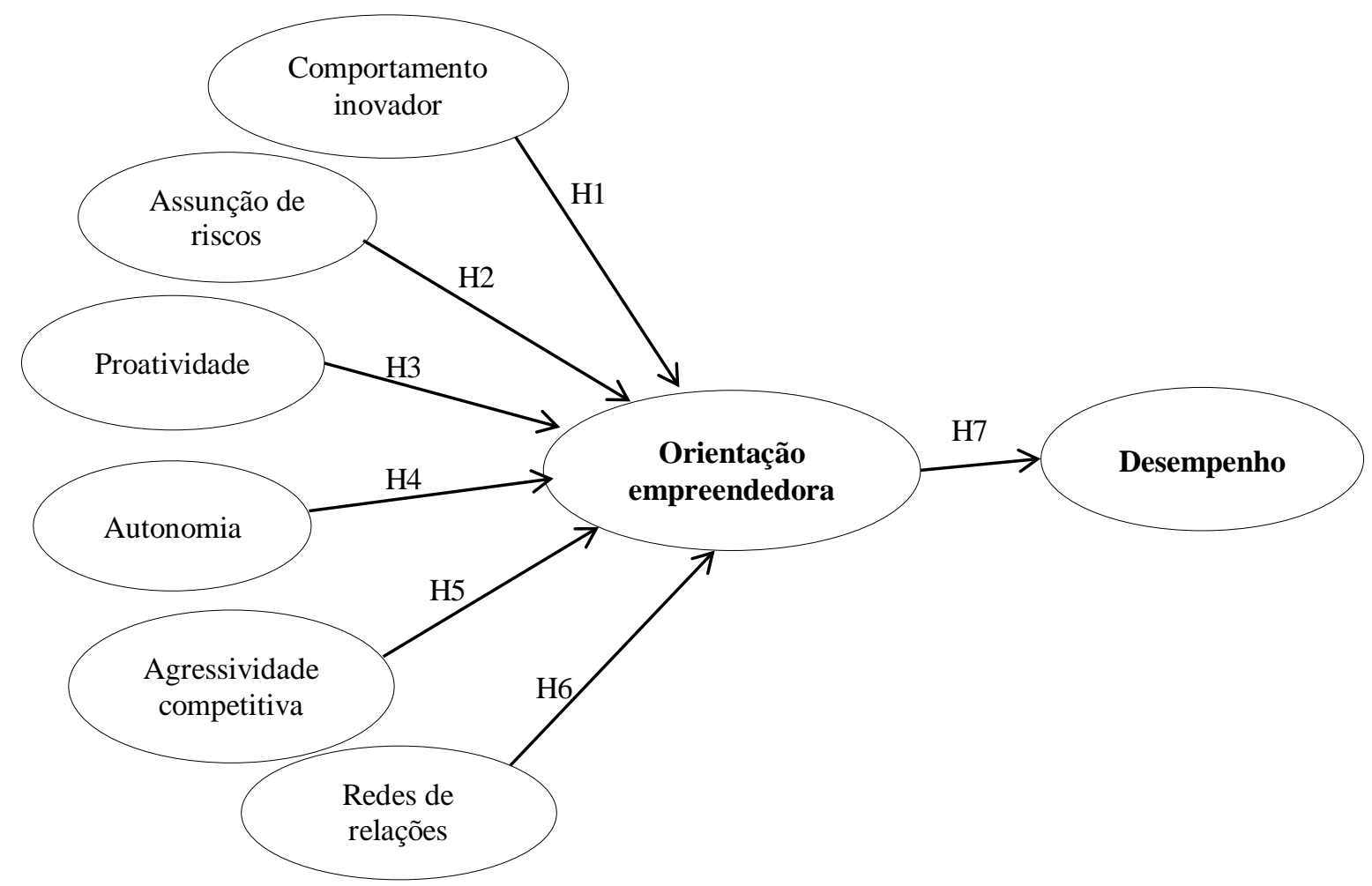

H1: O comportamento inovador contribui positivamente para a OE;

H2: A assunção de riscos afeta positivamente a OE;

H3: A proatividade impacta positivamente para a $\mathrm{OE}$;

H4: A autonomia contribui positivamente para a $\mathrm{OE}$;

H5: A agressividade competitiva afeta positivamente para a OE;

H6: As redes de relações contribuem positivamente para a OE;

H7: A Orientação Empreendedora (OE) impacta positivamente o desempenho.

Figura 1. Modelo de Estudo da Relação Entre os Construtos da Orientação Empreendedora Fonte: Adaptado de Miller, D. (1983). The correlates of entrepreneurship in three types of firms (p. 771). Management Science, 29(7), 770-791. doi: 10.1287/mnsc.29.7.770 e Lumpkin, G. T., \& Dess, G. G. (1996). Clarifying the entrepreneurial orientation construct and linking it to performance (pp. 149-151). Academy of Management Review, 21(1), 135-172. doi: 10.2307/258632 


\section{Procedimentos Metodológicos}

O estudo foi desenvolvido, predominantemente, pela abordagem da pesquisa quantitativa, do tipo levantamento ou survey, que visa descrever as características de uma determinada população ou o estabelecimento de determinadas variáveis (Gil, 1991).

A população pesquisada constituiu-se das empresas graduadas, que passaram pelo processo de incubação das incubadoras do Brasil, segundo dados da Associação Nacional de Entidades Promotoras de Empreendimentos Inovadores (ANPROTEC, 2012).

Foram obtidos 706 empresas para contato. Do total de empresas mapeadas, conseguiu-se o endereço eletrônico de 470 para o envio do questionário de pesquisa aos gestores e/ou responsáveis das empresas. Destas, após três tentativas em cada contato, 341 não retornaram e 1(uma) recusou-se a responder, o que resultou em uma amostragem, do tipo intencional, de 128 respondentes oriundos de vários estados do Brasil, com destaque para SC (18,0\%), RS (16,3\%), SP (16,3\%), PR (12,4\%), MG $(13,2 \%)$ e RJ $(8,5 \%)$. Os demais estados em que as empresas graduadas retornaram com questionários respondidos foram BA, CE, DF, MT, PB, RN e TO, que representaram 15,3\% do total da amostra. O período da realização da coleta de dados foi de outubro a novembro de 2012.

Justifica-se a escolha dessa população em razão do tempo de existência, certamente maior que o das incubadas, para permitir o teste das hipóteses de pesquisa e fazer uma análise comparativa com resultado da pesquisa de A. C. M. Z. Santos e Alves (2009), que tomou por base somente as empresas incubadas.

Os sujeitos de pesquisa foram os empreendedores ou proprietários/gerentes executivos, que tinham conhecimento da forma de atuação da empresa e seus respectivos resultados financeiros. Como instrumento de coleta de dados, foi utilizado o questionário, do tipo estruturado, com escala de concordância likert de sete pontos e em meio eletrônico, baseado nos construtos e variáveis observadas conforme A. C. M. Z. Santos e Alves (2009). A Tabela 1 traz cada um dos indicadores dos construtos utilizados nesta pesquisa.

Tabela 1

\section{Construtos e Indicadores do Modelo}

\begin{tabular}{lll}
\hline Construtos & Indicadores & Siglas \\
\hline $\begin{array}{l}\text { Comportamento } \\
\text { inovador }\end{array}$ & Investimento em pesquisa e desenvolvimento (P\&D) & INOV1 \\
& Introdução de novos produtos/serviços nos últimos três anos & INOV2 \\
& Busca de formas diferentes para realizar ações e solucionar problemas & INOV3 \\
\hline Assunção de riscos & Atuação em projetos de alto risco & RIS1 \\
& Coloca-se em situações de risco para explorar oportunidades & RIS2 \\
& Realização de empréstimos financeiros & RIS3 \\
\hline Proatividade & Pioneirismo na implementação de produtos/serviços/tecnologias & PRO1 \\
& Iniciativas que causam reações na concorrência & PRO2 \\
& Monitoramento constante das necessidades dos clientes & PRO3 \\
\hline Autonomia & Incentivo à criatividade e às ações independentes nos colaboradores & AUT1 \\
& Possuir equipes autônomas & AUT2 \\
& Disponibilização de informações importantes para colaboradores & AUT3 \\
\hline
\end{tabular}




\section{Tabela 1 (continuação)}

\begin{tabular}{lll}
\hline Construtos & Indicadores & Siglas \\
\hline $\begin{array}{l}\text { Agressividade } \\
\text { competitiva }\end{array}$ & Busca constante pela participação de mercado & AGC1 \\
& Monitoramento e reação à ameaça dos concorrentes & AGC2 \\
& Enfrentar a competição, tirando o concorrente do mercado & AGC3 \\
\hline Redes de relaçães & Celebração de parcerias/acordos de cooperação & REL1 \\
& Adoção de estratégias deliberadas para influenciar os outros & REL2 \\
& Participação regular de reuniões sociais e encontros empresariais & REL3 \\
\hline Desempenho* $^{*}$ & Aumento de participação de mercado & DES1 \\
& Crescimento em volume de vendas & DES2 \\
& Lucratividade & DES3 \\
& Aumento do número de colaboradores contratados & DES4 \\
& Desempenho global melhor & DES5 \\
\hline
\end{tabular}

Nota. Fonte: Elaboradora a partir de Santos, A. C. M. Z., \& Alves, M. S. P. C. (2009, setembro). Dimensões da orientação empreendedora e seus diferentes impactos no desempenho de empresas instaladas em incubadoras tecnológicas da região sul do Brasil (p. 7). Anais do Encontro Nacional da Associação Nacional de Pós-Graduação e Pesquisa em Administração, São Paulo, SP, Brasil, 33.

* O construto desempenho foi mensurado a partir da percepção dos respondentes sobre os resultados da empresa do ano de 2011, comparado com o ano de 2010.

Depois da elaboração do questionário, o mesmo foi revisado por dois especialistas e transcrito para o programa google docs, que permitiu enviar o link da pesquisa diretamente aos endereços eletrônicos das empresas graduadas.

Quanto à técnica de análise dos dados, pela natureza da investigação e de modo a manter o padrão adotado por A. C. M. Z. Santos e Alves (2009), utilizou-se a técnica de análise da modelagem de equações estruturais (MEE) com o auxílio do software Análise de Estruturas de Momento (AMOS®), versão 18.0. Como estratégia de modelagem, com base em Hair, Black, Babin, Anderson e Tatham (2009), adotou-se a que trata de desenvolvimento de modelos. Ela tem por finalidade melhorar uma estrutura inicialmente apresentada a partir de modificações no modelo de mensuração ou estrutural, mediante base teórica.

Para avaliação do modelo de mensuração, utilizaram-se os índices de qualidade de ajuste (GOF), que possuem a função de indicar a similaridade entre as matrizes de covariância estimada e observada. Quanto mais bem ajustado for o modelo teórico, significa que ele consegue refletir potencialmente a realidade observada. As medidas utilizadas são mostradas na Tabela 2. 
Tabela 2

Medidas de Qualidade de Ajuste, Função e Análise, e Ajuste Esperado

\begin{tabular}{ll}
\hline Medidas de qualidade de ajuste & Ajuste esperado \\
\hline Qui-quadrado sobre graus de liberdade $\left(\chi^{2} / \mathrm{GL}\right)$ & $<3$ \\
Índice de qualidade de ajuste (GFI) & $>0,90$ \\
Raiz do erro quadrático médio de aproximação (RMSEA) & $<0,08$ \\
Índice de ajuste normado (NFI) & $>0,90$ \\
Índice de ajuste comparativo (CFI) & $>0,90$ \\
Índice de Tucker Lewis (TLI) & $>0,90$ \\
\hline
\end{tabular}

Nota. Fonte: Elaborado a partir de Hair, J. F., Jr., Black, W. C., Babin, B. J., Anderson, R. E., \& Tatham, R. L. (2009). Análise multivariada de dados (5a ed., pp. 653-656). Porto Alegre: Bookman; Byrne, B. M. (2010). Structural equation modeling with AMOS (2nd ed., pp. 161-164). New York: Routledge; e Kline, R. B. (2011). Principles and practice of structural equation modeling (3rd ed., pp. 193-204). New York: Guilford Press.

Como validade de construto, foi usada neste estudo a validade convergente por meio do uso da técnica de análise fatorial, a confiabilidade de construto e a variância extraída de cada construto.

\section{Apresentação e Discussão dos Resultados}

Com o propósito de analisar a orientação empreendedora e sua relação com desempenho das empresas graduadas a partir da orientação empreendedora e com base nos resultados de A. C. M. Z. Santos e Alves (2009), foram criados dois modelos alternativos para teste: multidimensional (M) e unidimensional $(\mathrm{U})$.

Observou-se que o modelo $\mathrm{M}$ não apresentou ajuste, tendo apresentado um qui-quadrado/GL de 4,299, CFI de 0,458 e RMSEA de 0,161. Além disso, o modelo apresentou estimativas de erros negativas em três indicadores, o que evidencia sua inadequação.

Como tentativas de ajustar o modelo, fez-se um refinamento do mesmo, identificando-se variáveis com menores cargas fatoriais padronizadas, que foram excluídas. Um construto excluído foi agressividade competitiva (AGC), que apresentou todos os indicadores com cargas inferiores ao esperado. De todos os outros construtos, com exceção de autonomia (AUT), foram eliminados indicadores que apresentaram cargas muito baixas.

Em seguida, testou-se novamente o modelo, sem o AGC e sem os indicadores com baixa carga fatorial (INOV3, RIS2, PRO3, REL2). Mesmo assim, o modelo apresentou baixo ajuste, com um quiquadrado/GL de 4,428; CFI de 0,635 e RMSEA de 0,164.

Tais resultados mostraram que o modelo multidimensional, representado pela Figura 2, não foi adequado para esta amostra. 


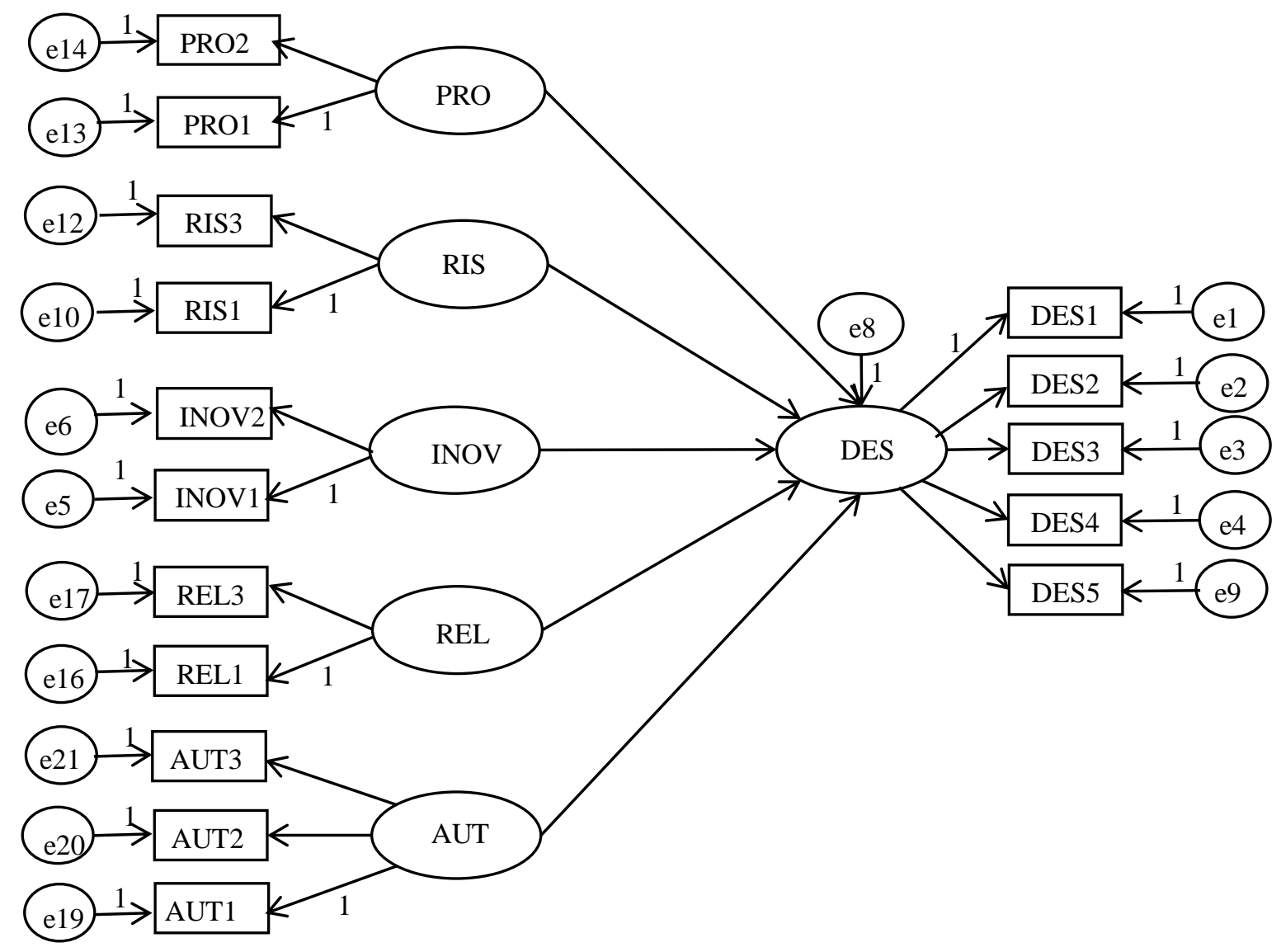

Figura 2. Modelo Estrutural Multidimensional da Orientação Empreendedora e sua Relação com Desempenho

Fonte: Saída dos dados do AMOS. (2009). (Versão 18.0) [Software]. Crawfordville, FL, USA: Amos Development Corporation.

Considerando que o modelo $M$ não foi adequado, optou-se por uma análise fatorial com os indicadores que apresentaram cargas fatoriais acima de 0,5. O resultado desta análise fatorial, pelo método de extração de análise do componente principal (Tabela 3), demonstrou que um único fator explica $50,881 \%$ da variância.

Tabela 3

\section{Matriz de Componente}

\begin{tabular}{ll}
\hline Indicadores & Componente \\
& $\mathbf{1}$ \\
\hline AUT1 &, 818 \\
AUT2 &, 711 \\
AUT3 &, 828 \\
PRO2 &, 573 \\
INOV3 &, 756 \\
REL1 &, 583 \\
REL3 &, 678 \\
\hline
\end{tabular}


Com isso, pode-se dizer que esses indicadores mensuram um construto unidimensional, uma vez que a análise gerou apenas um fator. Este único fator criado foi denominado de Orientação Empreendedora (OE), que confirma os estudos de Miller (1983) e Covin e Slevin (1989), porém, com indicadores diversos ao originalmente proposto. Dois destes indicadores tratam das redes de relações, aspecto não mencionado até então.

A partir do fator formado por estes indicadores, construiu-se um modelo unidimensional de equações estruturais, que foi testado levando-se em conta sua relação com desempenho, mensurado por cinco indicadores, conforme ilustra a Figura 3.

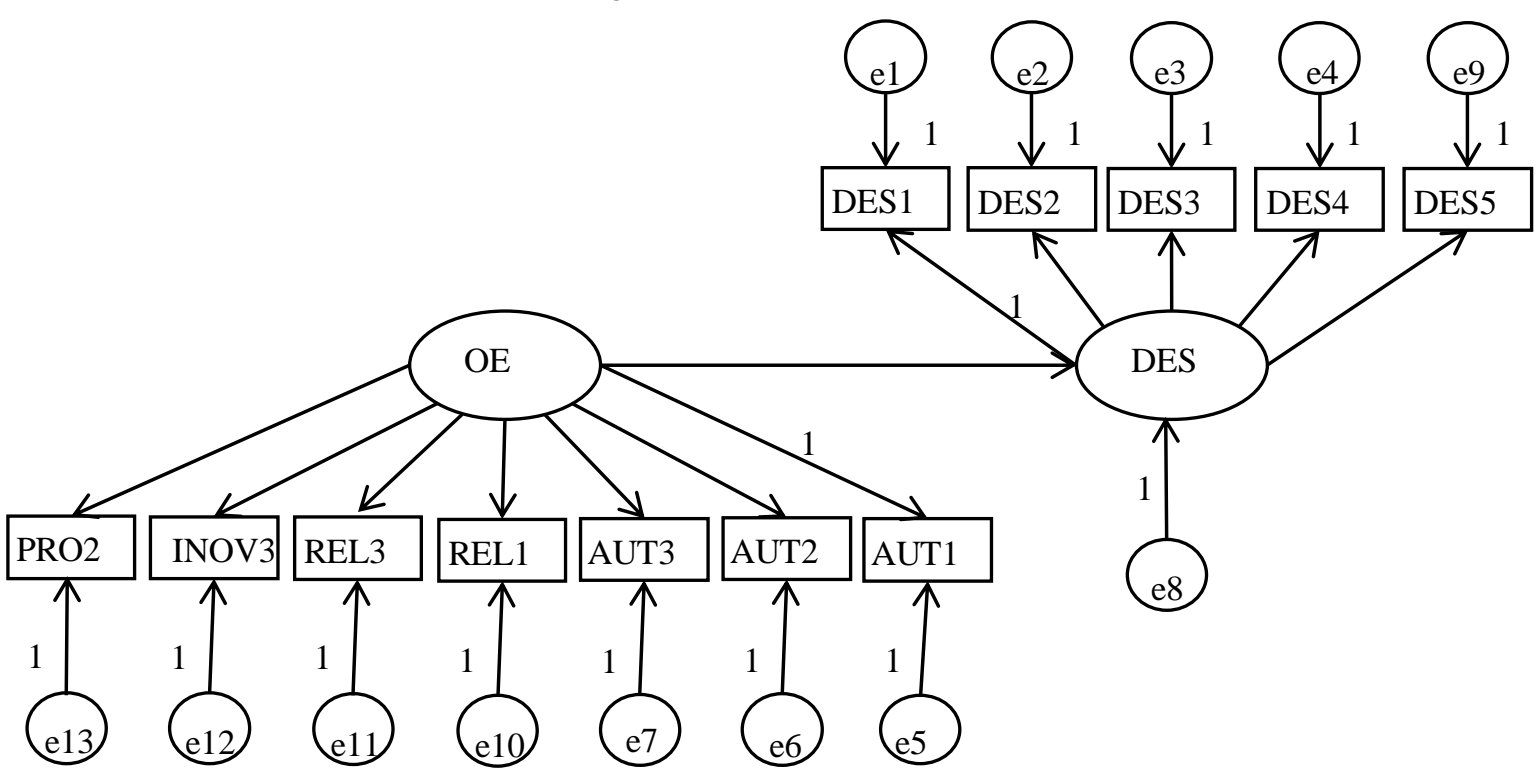

Figura 3. Modelo Estrutural Unidimensional da Orientação Empreendedora e sua Relação com Desempenho

Fonte: Saída dos dados do AMOS. (2009). (Versão 18.0) [Software]. Crawfordville, FL, USA: Amos Development Corporation.

Ao redefinir o novo modelo unidimensional (U) da OE, que manteve somente indicadores que apresentaram cargas fatoriais elevadas $(>0,50$ e $p<0,05)$, buscou-se avaliar novamente os índices de qualidade de ajuste do modelo, comparando-os com o modelo multidimensional (M), conforme mostra a Tabela 4 .

Tabela 4

Índices de Qualidade de Ajuste dos Modelos M e U

\begin{tabular}{lccccccccc}
\hline Modelos & $\chi^{2}$ & $\begin{array}{c}p \text {-valor } \\
>0,05\end{array}$ & GL & $\begin{array}{c}\chi^{2} / \mathrm{GL} \\
<3\end{array}$ & $\begin{array}{c}\text { GFI } \\
>0,90\end{array}$ & $\begin{array}{c}\text { NFI } \\
>0,90\end{array}$ & $\begin{array}{c}\text { TLI } \\
>0,90\end{array}$ & $\begin{array}{c}\text { CFI } \\
>0,90\end{array}$ & $\begin{array}{c}\text { RMSEA } \\
<0,08\end{array}$ \\
\hline Modelo M & 438,363 & 0,000 & 99 & 4,428 & 0,713 & 0,583 & 0,558 & 0,635 & 0,164 \\
Modelo U & 93,933 & 0,000 & 53 & 1,772 & 0,901 & 0,882 & 0,930 & 0,944 & 0,078 \\
\hline
\end{tabular}

De acordo com a Tabela 4, o modelo $\mathrm{U}$ apresenta todos os índices de qualidade de ajuste dentro do escore recomendado. No caso do Modelo M, conforme já salientado anteriormente, não há ajuste. A Tabela 5 mostra os resultados da estimação dos coeficientes de validade convergente para o modelo U da OE. 
Tabela 5

Estimação dos Coeficientes de Validade Convergente para o Modelo U da OE

\begin{tabular}{lccc}
\hline Variáveis & $\begin{array}{c}\text { Carga fatorial padronizada } \\
>0,50(p<0,05)\end{array}$ & $\begin{array}{c}\text { Confiabilidade composta } \\
>0,70\end{array}$ & $\begin{array}{c}\text { Variância extraída } \\
>0,50\end{array}$ \\
\hline AUT1 & 0,732 & 0,892 & 0,551 \\
AUT2 & 0,659 & & \\
AUT3 & 0,829 & & \\
REL1 & 0,474 & & \\
REL3 & 0,605 & & \\
INOV3 & 0,738 & & \\
PRO2 & 0,491 & & \\
\hline
\end{tabular}

Com base na Tabela 5, nota-se que somente a variável REL1 mostrou-se relativamente abaixo da carga fatorial padronizada, com carga de 0,474. No entanto, as demais variáveis mostraram cargas elevadas, o que se comprova na verificação da confiabilidade composta. Este resultado indica consistência interna dos indicadores de OE. A variância extraída, outra medida de confiabilidade do construto $\mathrm{OE}$, que reflete a quantia geral de variância nos indicadores, também foi evidenciada.

Na sequência, tem-se a Tabela 6 , que traz a estimação dos coeficientes da validade convergente do modelo U para as variáveis de desempenho.

Tabela 6

Estimação dos Coeficientes de Validade Convergente para o Modelo U do Desempenho

\begin{tabular}{lccc}
\hline Variáveis & $\begin{array}{c}\text { Carga fatorial padronizada } \\
>0,50(p<0,05)\end{array}$ & $\begin{array}{c}\text { Confiabilidade composta } \\
>0,70\end{array}$ & $\begin{array}{c}\text { Variância extraída } \\
>0,50\end{array}$ \\
\hline DES1 & 0,838 & 0,928 & 0,730 \\
DES2 & 0,905 & & \\
DES3 & 0,817 & & \\
DES4 & 0,464 & & \\
DES5 & 0,831 & & \\
\hline
\end{tabular}

Da mesma forma que a OE, somente uma variável (DES4) mostrou carga ligeiramente abaixo do intervalo esperado. No entanto, as demais cargas fatoriais foram elevadas, que é refletida também no atendimento da confiabilidade composta e da variância extraída.

Uma vez evidenciada a relação entre os indicadores dos construtos que permaneceram no modelo, passou-se à verificação do modelo estrutural para o teste das hipóteses, conforme mostra a Tabela 7. 
Tabela 7

Resumo do Teste de Hipóteses

\begin{tabular}{|c|c|c|c|c|c|}
\hline Hipótese & Relação esperada & Indicadores & $\begin{array}{c}\text { Coeficiente } \\
\text { padronizado }\end{array}$ & $p$-valor & Resultado \\
\hline H1 & $\mathrm{INOV} \Longrightarrow \mathrm{OE}$ & INOV3 & 0,738 & 0,000 & Suportada \\
\hline $\mathrm{H} 2$ & $\mathrm{RIS} \Longrightarrow \mathrm{OE}$ & - & - & - & N.A.* \\
\hline $\mathrm{H} 3$ & $\mathrm{PRO} \Longrightarrow \mathrm{OE}$ & $\mathrm{PRO} 2$ & 0,491 & 0,000 & Suportada \\
\hline \multirow[t]{3}{*}{$\mathrm{H} 4$} & $\mathrm{AUT} \rightleftharpoons \mathrm{OE}$ & AUT1 & 0,732 & 0,000 & Suportada \\
\hline & & AUT2 & 0,659 & 0,000 & \\
\hline & & AUT3 & 0,829 & 0,000 & \\
\hline H5 & $\mathrm{AGC} \Longrightarrow \mathrm{OE}$ & - & - & - & N.A. \\
\hline \multirow[t]{2}{*}{ H6 } & $\mathrm{REL} \Longrightarrow \mathrm{OE}^{1}$ & REL1 & 0,474 & 0,000 & Suportada \\
\hline & & REL3 & 0,605 & 0,000 & \\
\hline $\mathrm{H} 7$ & $\mathrm{OE} \rightleftharpoons \mathrm{DES}$ & - & 0,607 & 0,000 & Suportada \\
\hline
\end{tabular}

Nota. * Não avaliada: os indicadores de RIS e AGC não foram avaliados. Embora tenham mostrado um p-valor abaixo de 0,005, apresentaram baixas cargas fatoriais e sua inclusão no modelo prejudicou o ajuste deste.

As relações hipotetizadas, em que foi possível sua avaliação, foram suportadas. Destaque-se para a autonomia, em que todos os indicadores apresentaram coeficientes padronizados elevados. O resultado parece ser coerente, pois estas empresas não estão mais dentro de uma incubadora, onde até então recebiam um suporte técnico-operacional e de gestão mais intenso pelo vínculo que tinham com o habitat de inovação. A partir do momento em que foram desvinculadas das incubadoras, passaram a ter maior independência em suas formas de atuação no mercado.

Em relação à ausência de um indicador de risco, diferente do que era esperado, os indicadores relativos à assunção de risco não apresentaram cargas suficientes no modelo validado. Miller (1983) entendia que o comportamento empreendedor tipicamente englobaria os três conceitos e que, na ausência de um deles, teríamos algo como menos que empreendedor. Porém, Miller (2011), em revisão daquele trabalho, reforça o que já suspeitava: que o processo empreendedor poderia se manifestar diferente em diferentes contextos, e que os três componentes serviriam para uma captura coletiva do empreendedorismo nestes diversos contextos. Assim, assunção de risco seria encontrada tipicamente em pequenas firmas, inovação seria encontrada em firmas de alta tecnologia e proatividade seria encontrada em firmas maiores.

Miller (2011) ainda lembra que uma das principais mensagens do texto de 1983, aquela que dizia que a natureza e as configurações dos indicadores de empreendedorismo, mais do que os próprios componentes, variam conforme o contexto no qual ocorrem. É possível que o contexto de alta tecnologia no qual estão inseridas as empresas da amostra deste estudo as leve a contar mais com outros componentes da $\mathrm{OE}$, não tomando risco. Ainda, o processo de incubação pelo qual todas passaram pode tê-las ensinado a não assumir riscos desnecessários. Aliás, o próprio Miller (2011) afirma que o efeito dos três componentes no desempenho é distinto, e que a tomada de risco teria uma relação curvilínea com o desempenho, contribuindo positivamente para o seu alcance no início e prejudicando-o em um segundo momento.

Considerando o estágio no ciclo de vida das empresas da amostra, no qual todas já passaram da fase inicial dos desafios à sua sobrevivência, tais empresas graduadas podem ter aprendido a administrar o risco, ou mesmo estejam inclinadas a não aceitar novos riscos considerando que não estão mais inseridas no ambiente protetor das incubadoras. 
Em efeito, as empresas pesquisadas tendem também a apresentar comportamentos de menor agressividade competitiva e intensidade inovadora, com destaque para este último, que pode explicar a presença de apenas um indicador de inovação (INOV3). O achado indica que estas empresas estão mais propensas a implementar mais inovações do tipo incrementais, que demandam baixos investimentos em pesquisa e desenvolvimento, a obter inovações radicais, que implicam maiores investimentos e maiores riscos (Tidd, Bessant, \& Pavitt, 2008).

A variável de redes relações das empresas graduadas, proposto neste estudo como uma dimensão adicional da OE, foi aceita a partir dos indicadores REL1 e REL3. Estudos anteriores já haviam salientado que redes de relações é uma característica comportamental do empreendedor (Filion, 1991; McClelland, 1962). Contudo, verificou-se que este construto também integra a OE de empresas graduadas brasileiras.

Por conseguinte, constatou-se no teste do modelo estrutural que o construto OE impacta no desempenho, convergindo com o estudo de Miller (1983) e Covin e Slevin (1989).

Concernente ao relacionamento entre tempo de existência das empresas e intensidade da OE, temse que não há diferença estatisticamente significativa para os indicadores AUT1, AUT2 e REL3. Nos demais indicadores, percebe-se que a média da intensidade da OE tende a aumentar com o tempo de existência das empresas. A exceção foi AUT3, em que a média reduziu nas empresas com mais de 10 anos. Em PRO2, houve também uma redução no intervalo entre 3 e 5 anos, mas depois a média voltou a subir no intervalo seguinte. Vide a Tabela 8, que ilustra o comentado.

Tabela 8

Relacionamento entre Tempo de Existência e Intensidade da Orientação Empreendedora

\begin{tabular}{llccccc}
\hline Variáveis e período & N & Média & Desvio padrão & F & Sig \\
\hline AUT1 & Menos de 3 anos & 6 & 5,67 & 1,211 & & \\
& Entre 3 e 5 anos & 45 & 5,44 & 1,119 & & 0,829 \\
Entre 5 e 7 anos & 35 & 5,66 & 1,282 & 0,371 & \\
Entre 7 e 10 anos & 32 & 5,78 & 1,313 & & \\
Acima de 10 anos & 10 & 5,60 & 1,350 & & \\
Total & 128 & 5,61 & 1,225 & & \\
\hline AUT2 & Menos de 3 anos & 6 & 4,67 & 1,862 & & \\
& Entre 3 e 5 anos & 45 & 5,02 & 1,305 & & \\
Entre 5 e 7 anos & 35 & 5,20 & 1,511 & & \\
Entre 7 e 10 anos & 32 & 5,31 & 1,786 & \\
Acima de 10 anos & 10 & 3,90 & 2,079 & & \\
Total & 128 & 5,04 & 1,599 & & \\
AUT3 & Menos de 3 anos & 6 & 4,50 & 1,378 & & \\
Entre 3 e 5 anos & 45 & 5,04 & 1,086 & & \\
Entre 5 e 7 anos & 35 & 5,49 & 1,067 & & \\
Entre 7 e 10 anos & 32 & 5,72 & 1,114 & 2.648 \\
Acima de 10 anos & 10 & 5,30 & 1,418 & & \\
Total & 128 & 5,33 & 1,158 & & \\
& & & & \\
\hline
\end{tabular}




\section{Tabela 8 (continuação)}

\begin{tabular}{|c|c|c|c|c|c|c|}
\hline \multicolumn{2}{|c|}{ Variáveis e período } & \multirow{2}{*}{$\frac{\mathbf{N}}{6}$} & \multirow{2}{*}{$\frac{\text { Média }}{5,50}$} & \multirow{2}{*}{$\begin{array}{c}\text { Desvio padrão } \\
1,761\end{array}$} & \multirow[t]{2}{*}{$\mathbf{F}$} & \multirow[t]{2}{*}{ Sig } \\
\hline INOV3 & Menos de 3 anos & & & & & \\
\hline & Entre 3 e 5 anos & 45 & 5,53 & 1,014 & & \\
\hline & Entre 5 e 7 anos & 35 & 5,89 & 1,022 & 2,101 & 0,085 \\
\hline & Entre 7 e 10 anos & 32 & 6,22 & 1,099 & & \\
\hline & Acima de 10 anos & 10 & 5,70 & ,949 & & \\
\hline & Total & 128 & 5,81 & 1,092 & & \\
\hline \multirow[t]{6}{*}{ PRO2 } & Menos de 3 anos & 6 & 5,00 & 1,789 & & \\
\hline & Entre 3 e 5 anos & 45 & 4,47 & 1,590 & & \\
\hline & Entre 5 e 7 anos & 35 & 5,00 & 1,328 & 2,859 & 0,026 \\
\hline & Entre 7 e 10 anos & 32 & 5,56 & 1,645 & & \\
\hline & Acima de 10 anos & 10 & 5,70 & 1,767 & & \\
\hline & Total & 128 & 5,01 & 1,605 & & \\
\hline \multirow[t]{6}{*}{ REL1 } & Menos de 3 anos & 6 & 4,83 & 2,229 & & \\
\hline & Entre 3 e 5 anos & 45 & 5,40 & 1,053 & & \\
\hline & Entre 5 e 7 anos & 35 & 5,71 & 1,152 & & \\
\hline & Entre 7 e 10 anos & 32 & 6,22 & ,792 & 4,394 & 0,002 \\
\hline & Acima de 10 anos & 10 & 6,30 & ,823 & & \\
\hline & Total & 128 & 5,73 & 1,140 & & \\
\hline \multirow[t]{6}{*}{ REL3 } & Menos de 3 anos & 6 & 5,67 & 1,633 & & \\
\hline & Entre 3 e 5 anos & 45 & 5,00 & 1,537 & & \\
\hline & Entre 5 e 7 anos & 35 & 5,26 & 1,442 & 0,725 & 0,577 \\
\hline & Entre 7 e 10 anos & 32 & 5,53 & 1,606 & & \\
\hline & Acima de 10 anos & 10 & 5,50 & 1,716 & & \\
\hline & Total & 128 & 5,27 & 1,541 & & \\
\hline
\end{tabular}

\section{Considerações Finais}

Dentre os resultados encontrados neste estudo, com destaque para a influência da orientação empreendedora sobre o desempenho das empresas, verificou-se convergência com o encontrado por A. C. M. Z. Santos e Alves (2009). Isto é, empresas graduadas também foram impactadas positivamente pela orientação empreendedora. No entanto, a forma de contribuição do modelo é diferente. Enquanto a modelagem de A. C. M. Z. Santos e Alves (2009) mostrou que cada dimensão da OE contribui de forma independente em empresas incubadas do sul do país, nesta pesquisa, que considerou uma amostragem de empresas graduadas de incubadoras do Brasil, evidencia que as dimensões da OE mensuram um construto unidimensional.

Embora haja resultados adversos em alguns estudos, como o verificado em Lumpkin e Dess (2001), Hughes e Morgan (2007) e A. C. M. Z. Santos e Alves (2009), apontando que a OE é um construto multidimensional, tem-se nesta investigação que as dimensões comportamento inovador, proatividade, autonomia e redes de relações movem-se conjuntamente para a existência da OE. Tal 
resultado corrobora com estudos seminais deste tema, especialmente com Miller (1983) e Covin e Slevin (1989).

Das dimensões sustentadas no teste de hipóteses, ressaltam-se a autonomia e as redes de relações. A autonomia foi a dimensão que contribuiu mais fortemente na composição da OE. Este resultado significa que empresas que já passaram pelo processo de incubação, desvinculando-se das incubadoras, tendem a apresentar maior independência em suas ações e estratégias organizacionais. As redes de relações, dimensão proposta neste estudo para compor a $\mathrm{OE}$, demonstrou sua contribuição com as demais dimensões do construto. Este achado vai ao encontro do estudo de Filion (1991), ao ressaltar a importância das relações do empreendedor para o crescimento da empresa. Desse modo, entende-se que o desenvolvimento de uma rede de relações, de contatos ou de negócios, não se restringe somente à figura do empreendedor, como o sujeito que inova e responsável pela criação de novas combinações na economia (Schumpeter, 1983). As redes de relações também importam para o empreendedorismo corporativo nas organizações, sobretudo, nos empreendimentos potencialmente inovadores.

De outro lado, as dimensões de assunção de riscos e agressividade competitiva não apresentaram resultados satisfatórios, que pudessem ser testadas e validadas no modelo. Em relação à primeira, a explicação pode residir no fato de as organizações terem conquistado sua autonomia ao se graduarem das incubadoras de empresas. É possível que no período em que estavam incubadas, sentiam-se mais seguras para agir e arriscar em razão de terem um suporte técnico, administrativo, jurídico, tecnológico e comercial que, em geral, é fornecido pelas incubadoras às empresas incubadas. Ao se desvincularem das incubadoras, as empresas podem não estar mais recebendo este suporte, o que as leva a agir com maior cautela, além da provável aprendizagem obtida durante o processo de incubação para evitarem riscos desnecessários ou assumirem riscos moderados.

Sobre a agressividade competitiva, pressupõe-se que há certa relação com a assunção de riscos, uma vez que as ações observadas naquela variável trazem embutido algum tipo de risco. Outro aspecto a ser considerado trata das relações construídas pelas empresas, desde o período de incubação. Este relacionamento entre as empresas, mesmo que concorrentes, pode ter evoluído para uma parceria em determinadas áreas ou mercados ou para uma competição menos agressiva. Ainda, as inovações implementadas pelas empresas graduadas podem servir de barreira para competidores entrantes, o que reduz a necessidade das empresas a agirem agressivamente com seus concorrentes.

Portanto, os principais resultados evidenciaram que a $\mathrm{OE}$ constitui-se em um modelo unidimensional, a partir da amostra pesquisada de empresas graduadas na relação com desempenho, divergente do encontrado por A. C. M. Z. Santos e Alves (2009) em empresas incubadas. Constatou-se que a dimensão que contribuiu mais fortemente para a existência da OE foi a autonomia, e que as redes de relações, dimensão não mencionada até então pelos trabalhos anteriores sobre o tema em questão, colaborou de forma análoga às demais dimensões para a composição do construto OE, que pode sugerir uma nova implicação teórica para pesquisas desta área.

Quanto às implicações gerenciais, pode-se concluir que o desenvolvimento de uma rede de relações é relevante para a competitividade de empreendimentos inovadores, corroborando com estudos anteriores (Jenssen \& Nybakk, 2009; Lopes \& Souza, 2005; Sheng, 2008). Embora empresas graduadas tenham se desvinculado ou reduzido o seu vínculo com incubadoras e habitats de inovação, o uso das redes de relações pode ser um componente decisivo para o alcance de objetivos organizacionais.

As limitações do estudo referem-se ao campo amostral, ao contexto da pesquisa e à subjetividade das respostas, que se baseiam somente na percepção do respondente. Para estudos futuros, sugere-se a replicação deste modelo em contextos diferentes do contexto altamente tecnológico e de maturidade planejada, tipicamente vivido por empresas graduadas em incubadoras tecnológicas. Sugere-se ainda avaliar as seis dimensões propostas, especialmente assunção de risco e agressividade competitiva, que este estudo pode não ter captado tais dimensões ou que as empresas investigadas não tenham apresentado uma OE elevada, visando criticar e/ou validar o modelo e comparar os resultados. 


\section{Referências}

Abreu, F. C., Souza, Y. S., \& Gonçalo, C. R. (2006, setembro). Aprendizagem e criação do conhecimento em incubadoras. Anais do Encontro Nacional da Associação Nacional de PósGraduação e Pesquisa em Administração, Salvador, BA, Brasil, 30.

AMOS. (2009). (Versão 18.0) [Software]. Crawfordville, FL, USA: Amos Development Corporation.

Associação Nacional de Entidades Promotoras de Empreendimentos Inovadores. (2012). Estudo, análise e proposições sobre as incubadoras de empresas no Brasil - relatório técnico. Recuperado http://www.anprotec.org.br/ArquivosDin/Estudo_de_Incubadoras_Resumo_web_2206_FINAL_pdf_59.pdf

Basile, A. (2012). Entrepreneurial orientation in smes: risk-taking to entering international markets. Far East Journal of Psychology and Business, 7(2), 1-17.

Byrne, B. M. (2010). Structural equation modeling with AMOS (2nd ed.). New York: Routledge.

Carland, J. W., Hoy, F., Boulton, W. R., \& Carland, J. A. C. (1984). Differentiating entrepreneurs from small business owners: a conceptualization. Academy of Management Review, 9(2), 354-359. doi: 10.5465/AMR.1984.4277721

Covin, J. G., \& Miller, D. (2014). International entrepreneurial orientation: conceptual considerations, research themes, measurement issues, and future research directions. Entrepreneurship Theory and Practice, 38(1), 11-44. doi: 10.1111/etap.12027

Covin, J. G., \& Slevin, D. P. (1989). Strategic management of small firms in hostile and benign environments. Strategic Management Journal, 10(1), 75-87. doi: 10.1002/smj.4250100107

Degen, R. (1989). O empreendedor: fundamentos da iniciativa empresarial (8a ed.). São Paulo: Makron Books.

Dolabela, F. (1999a). Oficina do empreendedor: a metodologia de ensino que ajuda a transformar conhecimento em riqueza. São Paulo: Cultura Editores Associados.

Dolabela, F. (1999b). O segredo de Luísa. São Paulo: Cultura Editores Associados.

Drucker, P. F. (1986). Innovation and entrepreneurship: practice and principles. New York: Harper \& Row.

Etzkowitz, H. (2002). Incubation of incubators: innovation as a triple helix of university industrygovernment networks. Science and Public Policy, 29(2), 115-128. doi: $10.3152 / 147154302781781056$

Fernandes, D. D. H., \& Santos, C. P. (2008). Orientação empreendedora: um estudo sobre as consequências do empreendedorismo nas organizações. RAE-eletrônica, 7(1). Recuperado de http://www.scielo.br/pdf/raeel/v7n1/a07v7n1.pdf. doi: 10.1590/S1676-56482008000100007

Filion, L. J. (1991). O planejamento do seu sistema de aprendizagem empresarial: identifique uma visão e avalie o seu sistema de relações. Revista de Administração de Empresas, 31(3), 63-71. Recuperado de http://www.scielo.br/pdf/rae/v31n3/v31n3a06.pdf. doi: 10.1590/S003475901991000300006

Filion, L. J. (1999). Empreendedorismo: empreendedores e proprietários-gerentes de pequenos negócios. Revista de Administração, 34(2), 5-28. 
Gil, A. C. (1991). Como elaborar projetos de pesquisa. São Paulo: Atlas.

Gonçalves, A. (2003, setembro). Da garagem para o sucesso. Revista Empreendedor, (107), p. 19.

Grégoire, D. A., Noël, M. X., Déry, R., \& Béchard, J.-P. (2006). Is there conceptual convergence in entrepreneurship research? A co-citation analysis of frontiers of entrepreneurship research 19812004. Entrepreneurship: Theory \& Practice, 30(3), 337-373. doi: 10.1111/j.15406520.2006.00124.x

Hair, J. F., Jr., Black, W. C., Babin, B. J., Anderson, R. E., \& Tatham, R. L. (2009). Análise multivariada de dados (5a ed.). Porto Alegre: Bookman.

Hisrich, R. D., \& Peters, M. P. (2004). Empreendedorismo (5a ed.). Porto Alegre: Bookman.

Hughes, M., \& Morgan, R. E. (2007). Deconstructing the relationship between entrepreneurial orientation and business performance at the embryonic stage of firm growth. Industrial Marketing Management, 36(5), 651-661. doi: 10.1016/j.indmarman.2006.04.003

Jenssen, J. I., \& Nybakk, E. (2009). Inter-organizational innovation promoters in small, knowledgeintensive firms. International Journal of Innovation Management, 13(3), 441-466. doi: $10.1142 / \mathrm{S} 1363919609002376$

Kline, R. B. (2011). Principles and practice of structural equation modeling (3rd ed.). New York: Guilford Press.

Lei n. 10.973, de 02 de dezembro de 2004. (2004). Dispõe sobre incentivos à inovação e à pesquisa científica e tecnológica no ambiente produtivo e dá outras providências. Diário Oficial da União da República Federativa do Brasil. Brasília, DF: Ministério da Fazenda.

Leite, E. (2006). Empreendedorismo, inovação e incubação de empresas: lei de inovação. Recife: Bargago.

Lopes, G. S., Jr., \& Souza, E. C. L. (2005). Atitude empreendedora em proprietários-gerentes de pequenas empresas. Construção de um instrumento de medida. REAd. Revista Eletrônica de Administração, 11(6), 1-21.

Lumpkin, G. T., \& Dess, G. G. (1996). Clarifying the entrepreneurial orientation construct and linking it to performance. Academy of Management Review, 21(1), 135-172. doi: 10.2307/258632

Lumpkin, G. T., \& Dess, G. G. (2001). Linking two dimensions of entrepreneurial orientation to firm performance: the moderating role of environment and industry life cycle. Journal of Business Venturing, 16(5), 429-451. doi: 10.1016/S0883-9026(00)00048-3

Martens, C. D. P., \& Freitas, H. (2008). Orientação empreendedora nas organizações e a busca de sua facilitação. Gestão.Org - Revista Eletrônica de Gestão Organizacional, 6(1), 90-108. Recuperado de http://www.revista.ufpe.br/gestaoorg/index.php/gestao/article/viewFile/83/73

Matias-Pereira, J., \& Krugliaskas, I. (2005). Gestão da inovação: a lei de inovação tecnológica como ferramenta de apoio às políticas industrial e tecnológica do Brasil. RAE-eletrônica, 4(2). Recuperado de http://rae.fgv.br/sites/rae.fgv.br/files/artigos/10.1590_S167656482005000200004.pdf

McClelland, D. C. (1962). Business drive and national achievement. Harvard Business Review, 40(4), 99-112.

McClelland, D. C. (1972). A sociedade competitiva: realização e progresso social. Rio de Janeiro: Expressão e Cultura. 
Mello, S. C. B., \& Leão, A. L. M. S. (2005). Compreendendo a orientação empreendedora de empresas de alta tecnologia. In E. C. L. Souza \& T. A. Guimarães (Orgs.), Empreendedorismo além do plano de negócios (pp. 162-178). São Paulo: Atlas.

Mello, S. C. B., Paiva, F. G. de, Jr., Souza, A. F., Neto, \& Lubi, L. H. O. (2006). Orientação empreendedora e competências de marketing no desempenho organizacional: um estudo em empresas de base tecnológica. Organizações \& Sociedade, 13(36), 185-202. doi: 10.1590/S198492302006000100010

Miller, D. (1983). The correlates of entrepreneurship in three types of firms. Management Science, 29(7), 770-791. doi: 10.1287/mnsc.29.7.770

Miller, D. (2011). Miller (1983) revisited: a reflection on EO research and some suggestions for the future. Entrepreneurship Theory and Practice, 35(5), 873-894. doi: 10.1111/j.15406520.2011.00457.x

Oberg, C., \& Grundström, C. (2009). Challenges and opportunities in innovative firms' network development. International Journal of Innovation Management, 13(4), 593-613. doi: $10.1142 / \mathrm{S} 1363919609002431$

Paiva, F. G. de, Jr., Fernandes, N. C. M., \& Almeida, L. F. L. (2010). A competência de relacionamento contribuindo para o desenvolvimento de capital social da empresa de base tecnológica. Revista de Negócios, 15(1), 11-28.

Santos, A. C. M. Z., \& Alves, M. S. P. C. (2009, setembro). Dimensões da orientação empreendedora e seus diferentes impactos no desempenho de empresas instaladas em incubadoras tecnológicas da região sul do Brasil. Anais do Encontro Nacional da Associação Nacional de Pós-Graduação e Pesquisa em Administração, São Paulo, SP, Brasil, 33.

Santos, M. (1977). Sociedade e espaço: a formação social como teoria e como método. Boletim Paulista de Geografia, (54), 81-99.

Sheng, H. H. (2008). Modelos de financiamento baseados em relações pessoais: experiência de empreendedores chineses no Brasil. Revista de Administração Contemporânea, 12(3), 741-761. doi: $10.1590 /$ S1415-65552008000300007

Schumpeter, J. A. (1942). Capitalism, socialism and democracy. New York: Haper and Brothers

Schumpeter, J. A. (1983). The theory of economic development. Cambridge, Mass: Harvard University Press.

Stoner, J. A. F., \& Freeman, R. E. (2009). Administração (5a ed., A. Calado, Trad.). Rio de Janeiro: LTC. (Obra original publicada em 1985)

Tidd, J., Bessant, J., \& Pavitt, K. (2008). Gestão da inovação (3a ed.). Porto Alegre: Bookman.

Tranjan, R. A. (2003, setembro). Qual é o seu mercado? Revista Empreendedor, Ano 9, (107), p. 16.

Zoschke, A. C. K., \& Lima, E. O. (2006, setembro). Marketing empreendedor e redes de relação: um estudo sobre micro, pequenas e médias empresas. Anais do Encontro Nacional da Associação Nacional de Pós-Graduação e Pesquisa em Administração, Salvador, BA, Brasil, 30. 


\section{Dados dos Autores}

Fábio Lazzarotti

Av. Nereu Ramos, 3777-D, 89813-000, Chapecó, SC, Brasil. E-mail: fabio.lazzarotti@unoesc.edu.br

Alissane Lia Tasca da Silveira

Rua João Pereira dos Santos, 305, Ponte do Imaruim, 88130-475, Palhoça, SC, Brasil. E-mail: alissane.silveira@ gmail.com

Carlos Eduardo Carvalho

Av. Nereu Ramos, 3777-D, 89813-000, Chapecó, SC, Brasil. E-mail: cec.unc@ hotmail.com

Carlos Ricardo Rossetto

Rua João Coan, 400, Centro, 88160-000, Biguaçu, SC, Brasil. E-mail: rossetto@univali.br

Jonatha Correia Sychoski

Rua Getúlio Vargas, 2125, 89600-000, Joaçaba, SC, Brasil. E-mail: jonatha521 @hotmail.com 